\title{
EFFECT OF TOPICAL STEROID THERAPY OF BULLOUS EROSIVE LICHEN PLANUS ON SERUM AND SALIVARY LEVELS OF ADVANCED GLYACATION END PRODUCTS
}

\author{
Wesam Abdel Moneim*, Amira Maged ${ }^{* *}$ and Olfat Shaker**
}

\begin{abstract}
Introduction: Lichen planus is a relatively common chronic inflammatory disease. The bullous erosive type is characterized by the high risk of developing squamous cell carcinoma. AGEs are believed to generate chronic inflammation.

Methodology: The study was carried on thirty participants; they were divided into two groups. Group (1): included 15 healthy participants free of any systemic diseases. Group (2): included 15 patients of bullous erosive oral lichen planus and free of any other diseases. Serum and salivary samples were taken from all participants at initial visit and after complete resolution of the lesions in the OLP patients using topical application of $0.1 \%$ or $0.05 \%$ betamethasone valerate gel.
\end{abstract}

Results: In serum, whether before or after treatment, OLP group showed statistical significantly higher mean AGE levels than the control group. In saliva, before treatment, OLP group showed statistical significantly higher mean AGE levels than the control group. After treatment, there was a statistically significant decrease in AGE level.

Conclusion: Both salivary and serum levels of AGE are valuable biomarkers in diagnosis and prognosis of OLP. Detection of AGE level in saliva can be considered as a valuable non-invasive method for diagnosis and prognosis of OLP.

KEYWORDS: advanced glycation end products, Oral lichen planus, saliva

\section{INTRODUCTION}

Lichen planus is a relatively common disorder all over the world, it is found to affect nearly $0.5 \%$ to $2.0 \%$ of the general population (McCreary \& McCartan, 1999). It is defined as a chronic inflammatory disease that can affect both mucosal and cutaneous tissues. Oral lichen planus (OLP) is known to occur more frequently than the cutaneous form and tend to be more persistent and more resistant to treatment (Mollaoglu, 2000).

\footnotetext{
* Associate Professor at Oral Medicine, and Periodontology Department, Faculty of Dentistry, Cairo University.

** Professor at Biochemistry Department, Faculty of Medicine, Cairo University
} 
OLP is characterized by a cellular inflammatory infiltrate which is found to consist mostly of CD4+ cells, presence of acidophilic bodies that represent the apoptotic epithelial cells, and also vacuolating degeneration of the basal epithelial layer (Krupaa et al, 2005).

The classic skin lesions of the lichen planus is described as purplish, polygonal, planar, pruritic papules and/or plaques (Katta, 2000).

OLP is most commonly detected in the buccal mucosa of middle-aged females more frequently than males. It can also be encountered on other areas such as the tongue, gingiva and lips. Multiple configurations can be noted, the most frequent pattern is the white reticular form, which is associated with interlacing white keratotic lines or striae (Wickham's striae) that produce an annular or lacy pattern. Clinically, the plaque form of oral lichen planus may resemble leukoplakia. The second form is the erythematous or atrophic form that might be seen in conjunction with reticular or erosive variants. Finally, the erosive form of lichen planus, where the central area of the lesion is mostly ulcerated. The bullous type is generally short lived as it ruptures leaving a painful ulcer (Regezi et al, 2012).

Previous studies had described the abnormal expression patterns of different inflammation-related cytokines, such as IL-1, 2, 4, 5, 6, 8, 10, 12, 17, 18, IFN- $\gamma$, TGF- $\beta$, and TNF- $\alpha$, in different media such as tissues, saliva, serum as well as peripheral blood mononuclear cells from OLP patients, which may reflect the immune deregulation condition and play a central role in the immune-pathogenesis of OLP (Lu et al, 2015).

OLP is known to have a high risk of developing squamous cell carcinoma approximately 10 times higher than that in the unaffected general population (Drangsholt et al, 2001).

Till now, no real cure for OLP was found. The target of all modalities of management of OLP is to achieve reduction of both length and severity of the symptoms. The most widely accepted treatment modality for OLP involves topical or systemic corticosteroids which aim to modulate the patient's immune response. Topical corticosteroids are the mainstay in treatment of mild to moderately symptomatic lesions and to avoid the side effects of the prolonged use of systemic steroids (Paul et al, 2002).

Advanced glycation end products (AGEs) formation is considered as a physiological process, with a consequently slow accumulation in human tissues which is found during ageing. On the other hand, more intense and rapid accumulation was encountered in patients with constant hyperglycemia and persistent oxidative or carbonyl stress (Papagrigoraki et al, 2017). Moreover, AGEs have been implicated in the pathophysiology of a variety of inflammatory and metabolic disorders (Papagrigoraki et al, 2017).

AGEs are produced by the non-enzymatic glycation of macromolecules which in turn accumulate in a number of different tissues (Sell $\&$ Monnier, 1989) and (Verzijl et al, 2003).

The biological activities of AGEs are known to be mediated by specific receptors for AGE (RAGE) which upon activation, engage critical signaling pathways that are linked to the pro-inflammatory responses and activation of various inflammatory genes (Hofmann et al, 1999) and (Loeser et $\boldsymbol{a l}, \mathbf{2 0 0 5}$ ). The activation of RAGE stimulates production of copious amounts of matrix metallo proteinases (MMPs), and TNF- $\alpha$ (Yammani et al, 2006) and (Nah et al, 2008) which are known to have a central role in OLP (Michel et al, 2004).

AGEs, according to their time and dose dependent continuous accumulation, can be considered to be an etiological factor in carcinogenesis . Moreover, AGEs are considered to have a major role in the exacerbation and spreading of cancerous lesions and they are directly related to the aggressiveness and state of tumor lesions. The chronic inflammation and reactive oxygen species (ROS) formation which 
occur after RAGE-AGEs interaction is believed to generate the deleterious pathways which are followed by uncontrolled cell division (Petrescu et al, 2018).

Up to the author's knowledge, no previous studies correlated the serum and salivary levels of AGEs with OLP, therefore the present study tried to focus the light on the effect of topical steroid therapy of OLP on both serum and salivary levels of AGEs.

\section{SUBJECTS AND METHOD}

\section{I- Study population:}

The present study was conducted on a total of thirty subjects, twenty three females and seven males, ranging in age from 35-56 years. The participants were recruited from the outpatient clinic of Oral Medicine and Periodontology Department, Faculty of Dentistry, Cairo University. The study was performed from June 2015 to Sep 2017.

They were divided into the following two groups:

Group (1): included 15 healthy participants free of any systemic diseases as controls according to dental modification Cornell medical index

\section{(Abramson, 1966).}

Group (2): included 15patients of bullous erosive oral lichen planus and free of any other diseases according to dental modification Cornell medical index (Abramson, 1966).

All participants were informed of the nature and objectives of the study and willingness to come for the follow up visits till the end of the study. They were given written approval consent to sign.

\section{Inclusion criteria:}

They had no history, symptoms, and/or signs of any systemic infections and allergies. Furthermore, they were selected to be free of any detectable oral lesions other than OLP (bullous erosive type) which had to have the following criteria: (i) painful lesions (ii) no topical therapy for 2 weeks, and no systemic therapy of OLP for one month before the beginning of the study.

\section{Exclusion criteria:}

Pregnant or breast-feeding women or children patients, those who use corticosteroids or other immune-suppressive drugs, and smokers, all were excluded from the study.

\section{II- Time of Sampling \& clinical assessment:}

Serum and salivary samples were taken from all participants at initial visit.

Patients of OLP were treated by using topical application of $0.1 \%$ or $0.05 \%$ betamethasone valerate gel. Patients were instructed to apply a thin layer of the prescribed topical steroid up to 3 times a day, after meals and at bedtime (Jungell, 1991).

Another salivary and serum samples were taken from patients of OLP after complete resolution of the lesions.

Samples collection and drug prescription were performed by the same researcher (W.A.), while assessment was performed by the other researcher (A.M.).

The following procedures were performed for all participants in the study:

1- Pain scores: Pain scoring was carried on using the visual analog scale (VAS) $(0=$ no pain, $10=$ extreme pain). All patients were asked to mark a vertical line through a $10-\mathrm{cm}$ horizontal line to represent the level of pain they experienced. Patients were also asked to give history about the periods of remission and exacerbation (Hegarty et al, 2002).

2-Saliva collection: Un-stimulated whole saliva was collected from all subjects. Each individual was requested to abstain eating, drinking, as well as teeth brushing at least $60 \mathrm{~min}$ prior to collection. 
Saliva samples were collected between $8 \mathrm{a} . \mathrm{m}$. and 2 noon. Un-stimulated whole saliva was collected using the drooling technique. Each subject rinsed their mouth with water before saliva collection, and then the subject was asked to swallow to remove saliva from the mouth. The subject was seated upright, and leaned his/her head forward over a test tube with a funnel, allowing the saliva to drain into the tube. Whole saliva $(\sim 5 \mathrm{~mL})$ was obtained from each individual. During saliva collection, the test tube was placed on ice. At the end of the collection, any remaining saliva in the patient's mouth was expelled into the test tube.

\section{3-Serum collection}

Venous samples were obtained to measure the serum AGEs level using the ELISA technique after $12 \mathrm{~h}$ of fasting. Blood samples were collected in sterile tubes and allowed to clot at room temperature. Sera were isolated by centrifugation and stored frozen below -20 until assayed for the AGEs level.

\section{4-Saliva processing}

Saliva obtained was centrifuged at $15,000 \times \mathrm{g}$ (MPW-65R, MPW. Med Instrument, Warszawa, Poland) for $15 \mathrm{~min}$ at $4^{\circ} \mathrm{C}$ to remove insoluble material. Supernatant was divided into $1-\mathrm{mL}$ aliquots in pre-chilled cryotubes. The specimens were immediately frozen $\left(-80^{\circ} \mathrm{C}\right)$ until analysis

\section{Measurement of AGE level}

The level of AGE was measured using the sandwich Enzyme-Linked Immunosorbent Assay (ELISA) kit. The kit was provided by Bioassay Technology Laboratory, Shanghai, CHINA. AGEs were added to the wells which were pre-coated with AGEs monoclonal antibody. Then, after cubation, a biotin-conjugated anti-human AGEs antibody was added to bind to human AGEs. After incubation, unbound biotin-conjugated anti-human AGEs antibody was washed away during a washing step. Next step was addition of Streptavidin-HRP to bind to the biotin-conjugated anti-human AGEs antibody.
After incubation unbound Streptavidin-HRP was washed away during a washing step. The Substrate solution was then added and the color developed in proportion to the amount of human AGEs. Finally, the reaction was terminated by addition of acidic stop solution and absorbance was measured at $450 \mathrm{~nm}$.

\section{Statistical Analysis}

Numerical data were explored for normality by checking the distribution of data and using tests of normality (Kolmogorov-Smirnov and ShapiroWilk tests). Age, serum and salivary Advanced Glyacation product (AGE) levels data showed normal (parametric) distribution while pain and RAE scores showed non-normal (non-parametric) distribution. Parametric data were presented as mean, standard deviation (SD) and 95\% Confidence Interval $(95 \% \mathrm{CI})$ for the mean values while nonparametric data were presented as median and range values. For parametric data, Student's t-test was used to compare between age values in the two groups. Repeated measures ANOVA test was used to compare between AGE levels in the two groups as well as the changes within each group. Bonferroni's post-hoc test was used for pair-wise comparisons when ANOVA test is significant. For non-parametric data; Wilcoxon signed-rank test was used to study the changes after treatment in pain and RAE scores. Spearman's correlation coefficient was used to determine the correlation between pain, RAE scores and AGE levels. Qualitative data were presented as frequencies and percentages. Fisher's Exact test was used for comparisons between the groups. The significance level was set at $\mathrm{P} \leq 0.05$. Statistical analysis was performed with IBM SPSS Statistics for Windows, Version 23.0. Armonk, NY: IBM Corp.

\section{RESULTS}

\section{Demographic data:}

There was no statistically significant difference 
between mean age values in the two groups. There was also no statistically significant difference between gender distributions in the two groups.

TABLE (1) Mean, standard deviation (SD), frequencies (n), percentages and results of Student's t-test and Fisher's Exact test for comparisons of demographic data in the two groups

\begin{tabular}{cccc}
\hline & $\begin{array}{c}\text { LP } \\
(\mathrm{n}=15)\end{array}$ & $\begin{array}{c}\text { Control } \\
(\mathrm{n}=15)\end{array}$ & $P$-value \\
\hline Age (Years) & & & \\
Mean (SD) & $50.9(6.4)$ & $49.8(5.6)$ & 0.713 \\
\hline Gender [n (\%)] & & & \\
Male & $3(20)$ & $4(26.7)$ & 1.000 \\
Female & $12(80)$ & $11(73.3)$ & \\
\hline
\end{tabular}

*: Significant at $P \leq 0.05$

\section{A) PAIN}

\section{Changes after treatment in LP group}

There was a statistically significant decrease in pain scores $(P$-value $=0.011$, Effect size $=0.894)$ and RAE scores $(P$-value $=0.012$, Effect size $=$ 0.892) after treatment.

TABLE (2) Median, range values and results of Wilcoxon signed-rank test for comparison between pain and RAE scores before and after treatment within LP group

\begin{tabular}{ccccc}
\hline & $\begin{array}{c}\text { Before } \\
\text { treatment } \\
(\mathrm{n}=15)\end{array}$ & $\begin{array}{c}\text { After } \\
\text { treatment } \\
(\mathrm{n}=15)\end{array}$ & $\begin{array}{l}P \text {-value } \\
\text { Effect size } \\
(r)\end{array}$ \\
\hline Pain & $7(6-8)$ & $0.5(0-2)$ & $0.011^{*}$ & 0.894 \\
RAE & $16.8(9-42)$ & $2(2-6)$ & $0.012^{*}$ & 0.892 \\
\hline
\end{tabular}

*: Significant at $P \leq 0.05$

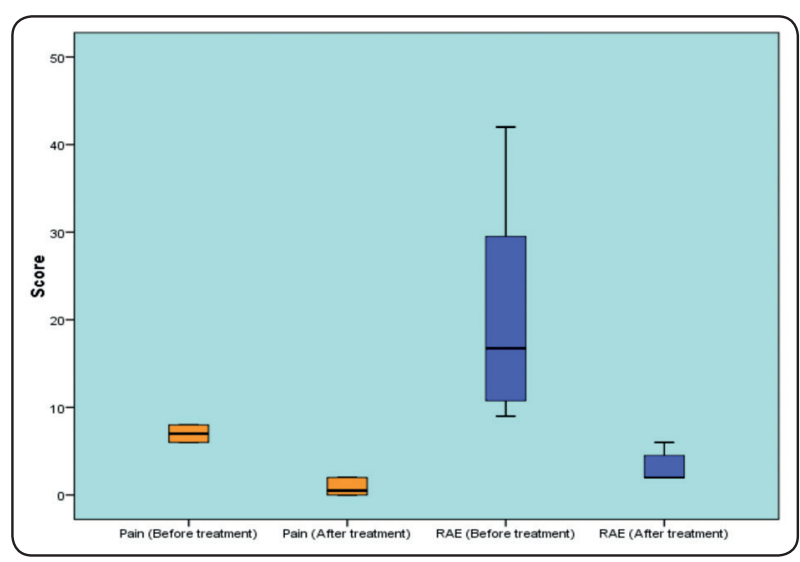

Fig. (1) Box plot representing median and range values for pain and RAE scores before and after treatment

\section{B) Advanced Glyacation product (AGE) levels}

\section{Comparison between the two groups}

In serum either before or after treatment, LP group showed statistical significantly higher mean AGE levels than control group $(P$-value $<0.001$, Effect size $=0.759)$ and $(P$-value $=0.025$, Effect size $=0.310)$, respectively.

In saliva before treatment, OLP group showed statistical significantly higher mean AGEs levels than control group $(P$-value $=0.001$, Effect size $=$ $0.565)$. After treatment, there was no statistically significant difference between AGE levels in the two groups $(P$-value $=0.073$, Effect size $=0.212)$.

\section{Changes after treatment in OLP group}

Whether in serum or saliva, there was a statistically significant decrease in AGE levels after treatment $(P$-value $<0.001$, Effect size $=0.798)$ and $(P$-value $<0.001$, Effect size $=0.872)$, respectively.

\section{C) Correlation between pain, RAE scores and advanced glyacation end products (AGEs) levels in OLP group}

There was no statistically significant correlation between pain, RAE scores and AGEs levels in serum or saliva before and after treatment. 
TABLE (3) Descriptive statistics and results of repeated measures ANOVA test for comparison between AGE levels in the two groups and the changes within LP group

\begin{tabular}{|c|c|c|c|c|c|c|c|}
\hline \multirow[t]{2}{*}{ 峲 } & \multirow[t]{2}{*}{ Time } & \multicolumn{2}{|c|}{$\begin{array}{c}\text { LP } \\
(n=15)\end{array}$} & \multicolumn{2}{|c|}{$\begin{array}{l}\text { Control } \\
(\mathrm{n}=15)\end{array}$} & \multirow{2}{*}{$\begin{array}{c}P \text {-value } \\
\text { (Between } \\
\text { groups) }\end{array}$} & \multirow{2}{*}{$\begin{array}{c}\text { Effect size } \\
\text { (Partial Eta } \\
\text { Squared) }\end{array}$} \\
\hline & & Mean (SD) & $95 \% \mathrm{CI}$ & Mean (SD) & $95 \% \mathrm{CI}$ & & \\
\hline \multirow{4}{*}{ 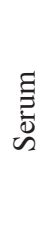 } & Before treatment & $916.2(144.3)$ & $795.6-1036.8$ & $476.1(119.6)$ & $376.2-576.1$ & $<0.001 *$ & 0.759 \\
\hline & After treatment & $669.1(181.9)$ & $517-821.1$ & $476.1(119.6)$ & $376.2-576.1$ & $0.025 *$ & 0.310 \\
\hline & $P$-value (Within group) & \multicolumn{2}{|c|}{$<0.001^{*}$} & \multicolumn{2}{|c|}{ - } & & \\
\hline & Effect size (Partial Eta Squared) & \multicolumn{2}{|c|}{0.798} & \multicolumn{2}{|c|}{ - } & & \\
\hline \multirow{4}{*}{ 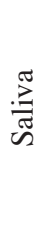 } & Before treatment & $281.9(110.4)$ & 189.6-374.3 & $172(15.5)$ & $159-184.9$ & $0.001 *$ & 0.565 \\
\hline & After treatment & $167.3(77.2)$ & $102.8-231.9$ & $172(15.5)$ & $159-184.9$ & 0.073 & 0.212 \\
\hline & $P$-value (Within group) & \multicolumn{2}{|c|}{$<0.001 *$} & \multicolumn{2}{|c|}{-} & & \\
\hline & Effect size (Partial Eta Squared) & \multicolumn{2}{|c|}{0.872} & \multicolumn{2}{|c|}{ - } & & \\
\hline
\end{tabular}

\section{*: Significant at $P \leq 0.05$}

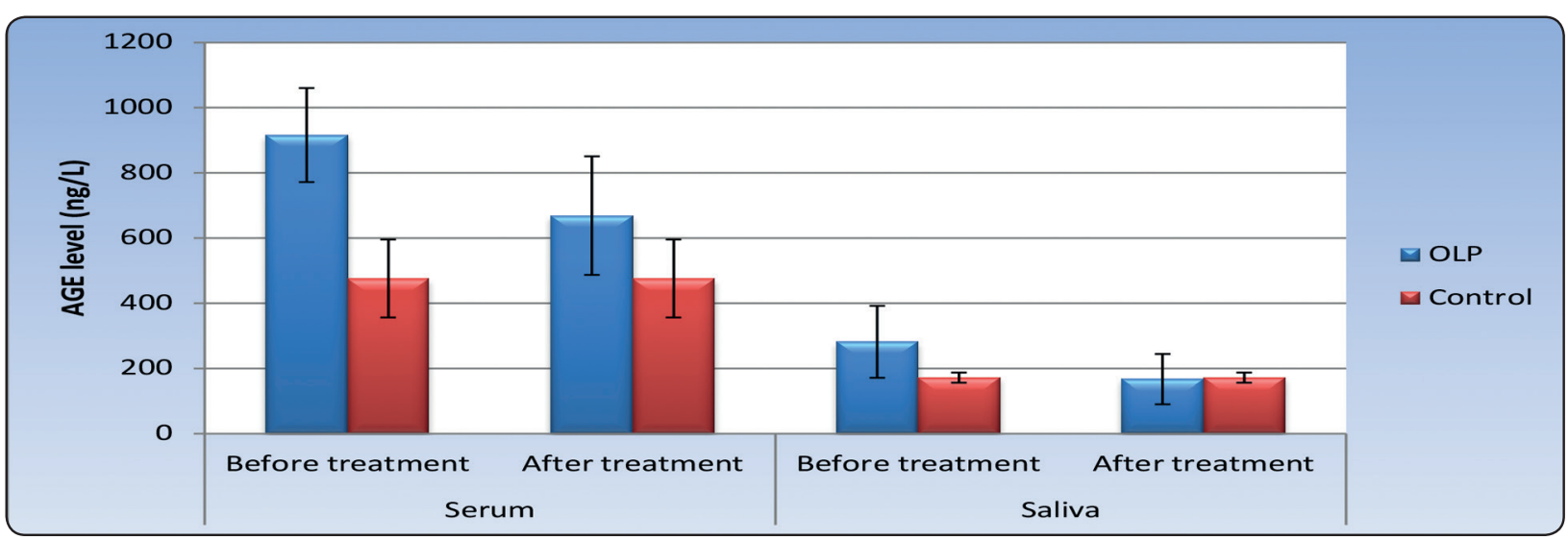

Fig. (2) Bar chart representing mean and standard deviation values for AGE levels in the two groups

TABLE (4) Results of Spearman's correlation coefficients for the correlation between pain, RAE scores and AGE levels in LP group

\begin{tabular}{llcc}
\hline & & Correlation coefficient & $P$-value \\
\hline \multirow{5}{*}{ Before treatment } & 0.315 & 0.447 \\
& Serum AGE \& Pain & -0.216 & 0.608 \\
& Serum AGE \& RAE & 0.189 & 0.654 \\
& Salivary AGE \& Pain & -0.443 & 0.272 \\
\hline \multirow{3}{*}{ After treatment } & Salivary AGE \& RAE & -0.326 & 0.431 \\
& Serum AGE \& Pain & -0.619 & 0.102 \\
& Serum AGE \& RAE & 0.313 & 0.450 \\
& Salivary AGE \& Pain & -0.289 & 0.488 \\
\hline
\end{tabular}




\section{DISCUSSION}

Oral lichen planus is characterized by a cell-mediated inflammatory reaction against keratinocytes, extrinsic antigens or metabolites that are bound to or expressed by keratinocytes. Keratinocytes, along with $\mathrm{T}$ cells, are found to mediate basal cell death through triggering of apoptosis (Regezi et al, 2012) and (Yang et al. 2016). In addition, Langerhans cells, CD1a+ dendritic cells, and macrophages are detected as contributors to the severity of OLP through maintaining a higher level of different cytokines (Yang et al. 2016).and (Souto et al, 2016).

Production of the pro-inflammatory cytokine interleukin 1 (IL-1) leads to subsequent activation of several prostaglandin-mediated events, principally prostaglandin E2 level, via the action of the enzyme cyclooxygenase-2 (COX-2) on arachidonic acid (Eisen, 2002), in association with both pro-inflammatory (IFN- $\gamma$ and TNF-a) and immune-suppressive (TGF-b1) cytokines which are encountered in OLP (Khan et al, 2003) and (De Carli et al, 2016).

Some previous studies suggested that there is a great relation between high oxidative stress and low antioxidant activity in patients of OLP (Scully 1998). The increased oxidative stress or deficient antioxidant status has been shown to have an important role in the pathogenesis of several diseases (Mahajan et al, 2003). ROS that are produced during macrophage activity, such as superoxide anion radicals, hydroxyl radicals and hydrogen peroxides are generated as a host defense mechanism (Chaturvedi et al, 2004). The occurrence of severe oxidative stress leads subsequently to increased accumulation of ROSs that can damage the cells ( $\mathbf{N e}$ upane et al, 2008).

Many AGEs are formed by a combination of oxidation with glycation so the reaction is called glycoxidation. Products are then triggered by oxidative stress (Scheijen \& Schalkwijk, 2014).

AGEs are formed by glycoxidation in a process that takes place in weeks or months, it is an irreversible reaction, the high complexity, and diversity of AGEs formation makes clear why substances belonging to the group of AGEs are so heterogeneous regarding their chemical and physical properties (Sharma et al, 2015).

AGE- RAGE, interaction activates NADPH oxidases activity which in turn increases intracellular formation of ROS (Hofmann et al, 1999).

High level of ROS leads subsequently to AGEs formation, which triggers all described damaging mechanisms mediated by AGEs, and also activates the transcription factor nuclear factor kappa $\mathrm{B}(\mathrm{NF} x \mathrm{~B})$ which increases the expression of different pro-inflammatory cytokines such as interleukin-6, tumor necrosis factor and monocyte chemoattractant peptide 1 (MCP-1) as well as RAGE itself (Li\& Schmidt, 1997).

Keratinocytes, fibroblasts, dendritic cells and to a lesser extent endothelial cells and lymphocytes also express RAGE (Lohwasser et al, 2006).

AGEs are themselves known to be reactive molecules which through interaction with their receptors activate various molecular pathways in vivo, thus assumed to be involved in inflammation, immune response, cell proliferation and gene expression (Paraskevi and Markus, 2012).

Therefore, the present study tried to explore the effect of topical steroid therapy of OLP on both serum and salivary level of AGEs. Also, to detect if salivary AGE level can be used as a non-invasive diagnostic, prognostic biomarker for OLP.

The current study detected no statistically significant difference regarding both the mean age values and gender distributions in the two groups.

Regarding the pain scores, the present study showed a statistically significant decrease in the pain scores after treatment using topical $0.1 \%$ or $0.05 \%$ betamethasone valerate gel. These results are consistent with (Hegarty et al, 2002) who compared betamethasone sodium phosphate mouth rinse with fluticasone propionate spray and found that both interventions were effective in improving pain scores. 
Similarly, in a Cochrane review of placebo controlled randomized clinical trials, improvement of signs and symptoms were observed after 8 weeks of therapy (Eisen et al, 2005).

Furthermore, one randomized comparative study showed that betamethasone oral mini-pulse therapy improved the clinical features in patients with moderate to severe OLP and it was similar in effectiveness to topical triamcinolone acetonide $0.1 \%$ paste (Malhotra et al, 2008). In addition, a previous study showed that betamethasone valerate aerosol induced remarkable clinical improvement when compared with placebo. Another study revealed superior improvement of OLP using betamethasone valerate pellets when compared to hydrocortisone pellets (Tyldesley, \& Harding, 1977) and (Melville, \& Fougera, 2012).

Regarding the AGEs levels in the serum, OLP group showed statistically significantly higher mean AGEs levels than control group respectively either before or after treatment.

Up to the author's knowledge, no previous studies performed to explore the correlation between AGEs and OLP.

However, in the immune-staining study performed by Salem et al (2018), a very strong staining for both RAGE, and toll-like receptor-4 (TLR4) TLR4 overexpression throughout OLP mucosa was detected. This explains the pro-inflammatory loop cycle that is created via RAGE- and TLR4-signalling axes in OLP, which may contribute to the chronicity of OLP.

Based on these observations, AGEs have a central role in inflammation, immune response, cell proliferation and gene expression as mentioned by Paraskevi \& Markus in 2012. Therefore, AGEs are proposed to be involved in the pathogenesis of different diseases such as, atherosclerosis, acute stroke, myocardial infarction, and peripheral vascular disease (Beckma et al, 2002), diabetes and its vascular complications (Basta, et al, 2004) and ( Renard \& Van Obberghen, 2006).
At the same time, AGEs levels are increased in the skin and blood of patients with severe psoriasis and are found to be implicated in exacerbating cutaneous inflammation. In addition, AGEs released from psoriatic skin may increase the cardiovascular risk in the severe form of psoriasis (Papagrigoraki et al, 2017). Also Ko et al (2017) performed an in vitro study which proved that suppression of p53 protection gene resulted when cells were exposed to AGEs. This, in turn, could increase the degree of invasiveness of tumor cells. Similarly, another in vitro study performed by Peng et al, (2015), showed that down-regulated RAGE expression induced inhibition of all malignant cells properties of proliferation, migration and invasion.

Regarding salivary AGE levels before treatment, the present study, showed statistical significantly higher AGEs mean level in OLP group than in control group. After treatment, there was no statistically significant difference between AGE levels in the OLP group compared to control group. This is in agreement with (Pia Lopez et al, 2016) who detected significantly higher salivary levels of IgA and cortisol in the OLP patients than the control group.

Regarding AGEs level, whether in serum or saliva, the current study showed a statistically significant decrease after treatment. Similarly, Rhodus et al (2006) detected a significant decrease in the levels of TNF-alpha, IL-1-alpha, IL-6, and IL-8 following the dexamethasone treatment.

Similarly, Hamid Reza in 2018 revealed higher levels of IL-6 in saliva of OLP when compared with serum which suggest that measurement of AGEs in saliva may be more useful than serum for diagnostic and therapeutic aims.

In the present study, we tried to correlate pain, RAE scores and AGEs levels in serum and saliva in OLP group before and after treatment, but there was no statistically significant correlation in spite of the clinical improvement. On the other hand, Rhodus et al in 2006 showed that VAS value was decreased significantly with significant correlation with the decrease in IL- $1 \alpha$ and IL- 8 levels. 
According to the mentioned observations, saliva, which is correlated to other biological fluids, represents an accessible, non- invasive and friendly media for detection of different biomarkers (Behuliak et al., 2009; Guentsch et al., 2008; Sculley \& Langley-Evans, 2003).

Therefore, detection of AGEs level in saliva can be considered as a valuable non-invasive method for diagnosis and prognosis of OLP.

\section{REFERENCES}

1. Abramson JH. (1966). The Cornell Medical Index as an epidemiological tool. Am J Public Health N ; 56:287-298

2. Basta G, Schmidt A M, De Caterina R. (2004). Advanced glycation end products and vascular inflammation: implications for accelerated atherosclerosis in diabetes. Cardiovasc Res 63:582-592.

3. Beckman JA, Creager MA, Libby P. (2002). Diabetes and atherosclerosis: epidemiology, pathophysiology, and management. JAMA 287:2570 -2581.

4. Behuliak, M., Pálffy, R., Gardlik, R., Hodosy, J., Halcák, L., \& Celec, P. (2009). Variability of thiobarbituric acid reacting substances in saliva. Disease Markers, 26, 49-53. C

5. Chaturvedi UC, Shrivastava R, Upreti RK. (2004). Viral infections and trace elements: Complex interaction. Curr Sci 2004;87:1536-54.

6. De Carli JP, Linden MS, da Silva SO, Trentin MS, Matos Fde S, Paranhos LR. (2016) Hepatitis C and Oral Lichen Planus: Evaluation of their Correlation and Risk Factors in a Longitudinal Clinical Study. J Contemp Dent Pract 17: 27-31.

7. Drangsholt M, Truelove EL, Morton TH Jr, Epstein JB. (2001). A man with a thirty-year history of oral lesions. J Evid Base Dent Pract ; 1(2): 123-35)

8. Eisen D, Carrozzo M, Bagan JV, Thongprasom K (2005). Number V Oral lichen planus: clinical features and management. Oral Dis 11, 338-349

9. Eisen D. (2002). The clinical features, malignant potential, and systemic associations of oral lichen planus: a study of 723 patients. J Am Acad Dermatol 46: 207-214.

10. Guentsch, A., Preshaw, P., Bremer-Streck, S., Klinger, G., Glockmann, E., \& Sigusch, B. (2008). Lipid peroxidation and antioxidant activity in saliva of periodontitis patients: Effect of smoking and periodontal treatment. Clin Oral Invest, 12, 345-352. G
11. Hamid Reza Mozaffari, Roohollah Sharifi, and Masoud Sadeghi (2018). Cent Eur J Immunol; 43(1): 103-108.Interleukin-6 levels in the serum and saliva of patients with oral lichen planus compared with healthy controls: a meta-analysis study

12. Hegarty AM, Hodgson TA, Lewsey JD, Porter SR. (2002). Fluticasone propionate spray and betamethasone sodium phosphate mouthrinse: a randomized crossover study for the treatment of symptomatic oral lichen planus. J Am Acad Dermatol. Aug;47(2):271-9)

13. Hofmann MA, Drury S, Fu C, Caifeng Fu, Wu Qu, Akihiko T, Lu Y, Kambham N, Schmidt AM. (1999). RAGE mediates a novel proinflammatory axis: a central cell surface receptor for S100/calgranulin polypeptides. Cell ; 97: 889-901. https:// goo.gl/VnvC4v

14. Jungell P. Oral lichen planus. (1991). a review. Int J Oral Maxillofac Surg; 20(3):129-35

15. Katta R. (2000). Lichen planus. Am Fam Physician; 61(11):3319-28

16. Khan NF, Mohammad Saeed, SaimaChaudhary and FarkhandaGhafoor. (2013). Haematological Parameters and Recurrent Aphthous Stomatitis. Journal of the College of Physicians and Surgeons Pakistan 2013, Vol. 23 (2): 124-127.

17. Krupaa RJ, Sankari SL, Masthan KM, Rajesh E (2005) Oral lichen planus: An overview. J Pharm Bioallied Sci 7: S158161

18. Li J, Schmidt AM. (1997). Characterization and functional analysis of the promoter of RAGE, the receptor for advanced glycation end products. J Biol Chem. 1997; 272: 16498 16506.

19. Loeser RF, Yammani RR, Carlson CS, Chen H, Cole A, Im HJ,bursch LS, Yan SD. (2005). Articular chondrocytes express the receptor for advanced glycation end products: potential role in osteoarthritis. Arthritis Rheum; 52:2376-85.

20. Lohwasser C, Neureiter D, Weigle B, Kirchner T, Schuppan D. (2006). The receptor for advanced glycation end products is highly expressed in the skin and upregulated by advanced glycation end products and tumor necrosis factor-alpha. J Invest Dermatol.;126:291-9.

21. Lu R, Zhang J, Sun W, Du G, Zhou G. (2015). Inflammationrelated cytokines in oral lichen planus: an overview. J Oral Pathol Med. 44(1):1-14.

22. Mahajan A, Tandon 27. Hagfors L, Leanderson P, Sköldstam L, Andersson J, Johansson G. (2003). Antioxidant intake, plasma antioxidants and oxidative stress in a randomized, controlled, parallel, Mediterranean dietary intervention study on patients with rheumatoid arthritis. Nutr $\mathrm{J} ; 2: 5$. 
23. McCreary CE, McCartan BE. (1999). Clinical management of lichen planus. Brit J Oral Maxillofacial Surg; 37(5):338-43.

24. Michele DM, ignogna Stefano Fedele Lucio Lo Russo Lorenzo Lo Muzio Eduardo Bucci (2004). REVIEW Immune activation and chronic inflammation as the cause of malignancy in oral lichen planus: is there any evidence ? Oral Oncology Volume 40, Issue 2, February, Pages 120-130

25. Mollaoglu N. (2000). Oral lichen planus: a review. Brit J Oral Maxillofacial Surg; 38(4):

26. Nah SS, Choi IY, Lee CK, Oh JS, Kim YG, Moon HB, Yoo B. (2008). Effects of advanced glycation end products on the expression of COX-2, PGE2 and NO in human osteoarthritic chondrocytes. Rheumatology;47:425-31.

27. Neupane DP, Majhi S, Chandra L, Rijal S, Baral N. (2008). Erythrocyte glutathione status in human visceral leishmaniasis. Indian J Clin Biochem ;23:95-7.

28. Papagrigoraki A, Maurelli M, Del Giglio M, Gisondi P, Girolomoni G. (2017). Int J Mol Sci. Nov 20;18(11). pii: E2471. doi: 10.3390/ijms18112471.Advanced Glycation End Products in the Pathogenesis of Psoriasis.

29. Paraskevi Gkogkolou and Markus Böhm (2012). Advanced glycation end productsKey players in skin aging? Dermatoendocrinol. Jul 1; 4(3): 259-270.

30. Paul C. Edwards, BSc, MSc, DDS • • Robert Kelsch, DMD. (2002). Oral Lichen Planus: Clinical Presentation and Management (Lichen plan : présentation clinique et prise en charge) Vol. 68, $\mathrm{N}^{\circ} 8$ Journal de l'Association dentaire canadienne

31. Peng T, Hu M, Wu T, Chen Z, Zhang C, Huang S, Zhou X. (2015). Effects of high-mobility group box 1 knockdown on proliferation, migration and invasion of the HONE-1 human nasopharyngeal carcinoma cell line. Mol Med Rep 12: 75317537.

32. Petrescu Bianca Nausica1, Băbțan Anida-Maria, Sorițău Olga, Buhățel Dan , Ionel Anca , Feurdean Nicoleta Claudia, Boșca Adina Bianca, Câmpian Radu Septimiu and Ilea Aranka. (2018). (Stem Cells in Head and Neck Cancers Pathogenesis: Are Advanced ‘ůLJĐĂ $\theta \breve{Z} \hat{Y}$ End Products (AGEs) Involved?: Biochemistry \& Molecular Biology Journal ISSN 2471-8084 Vol.4 No.2:12.

33. Pia Lopez-Jornet, Cristina Aznar Cayuela, Asta Tvarijonaviciute, Francisco Parra-Perez, Damian Escribano, Jose Ceron. (2016). Oral lichen planus: salival biomarkers cortisol, immunoglobulin A, adiponectin J Oral Pathol Med 45: 211217 detected

34. Regezi JA, Sciubba JJ, Jordan RC (2012) Oral pathology: clinical pathologic correlations. Elsevier Health Sciences.

35. Renard C, Van Obberghen E. (2006). Role of diabetes in atherosclerotic pathogenesis: what have we learned from animal models? Diabete Metab 32:15-29.

36. Rhodus NL, Cheng B, Bowles W, Myers S, Miller L, Ondrey F. (2006). Proinflammatory cytokine levels in saliva before and after treatment of (erosive) oral lichen planus with dexamethasone. Oral Dis. 2006 Mar;12(2):112-6.

37. Scheijen JL, Schalkwijk CG. (2014). Quantification of glyoxal, methylglyoxal and 3-deoxyglucosonei n blood and plasma by ultra-performance liquid chromatography tandem mass spectrometry:Evaluation of blood specimen. Clin Chem Lab Med. 2014; 52: 85-91.

38. Sculley, D., \& Langley-Evans, S. (2003). Periodontal disease is associated with lower antioxidant capacity in whole saliva and evidence of increased protein oxidation. Clin A. Ilea et al. Archives of Oral Biology 93 (2018) 22-30 29 Sci (Lond), 105, 167-172

39. Scully C, Beyli M, Ferreiro MC, Ficarra G, Gill Y, Griffiths M, Holmstrup P, Multu S, Porter s, Wray D. (1998). Update on oral lichen planus: Etiopathogenesis and management. Crit Rev Oral Biol Med 1998;9:86-122.

40. Sell DR, Monnier VM. (1989). Structure elucidation of a senescence cross-link from human extracellular matrix: implication of pentoses in the aging process. J Biol Chem.; 264:21597-602.

41. Sharma C, Kaur A, Thind SS, Singh B, Raina S. (2015). Advanced glycation end-products (AGEs): an emerging concern for processed food industries. J Food Sci Techno. ; 52: 75617576

42. Souto GR, Nunes LF, Tanure BB, Gomez RS, Mesquita RA (2016). CD1a+ dendritic cells in oral lichen planus and amalgam lichenoid reaction. Oral Surg Oral Med Oral Pathol Oral Radiol 121: 651-656.].

43. Verzijl N, Bank RA, TeKoppele JM, DeGroot J. (2003). Ageing and osteoarthritis: a different perspective. Curr Opin Rheumatol;15:616-22.)

44. Yammani RR, Carlson CS, Bresnick AR, Loeser RF. (2006). Increase in production of matrix metalloproteinase $13 \mathrm{by} \mathrm{hu}$ man articular chondrocytes due to stimulation with S100A4: role of the receptor for advanced glycation end products. Arthritis Rheum. 2006;54:2901-11.

45. Yang H, Wu Y, Ma H, Jiang L, Zeng X, Dan H, Zhou Y, Chen Q. (2016). Possible alternative therapies for oral lichen planus cases refractory to steroid therapies. Oral Surg Oral Med Oral Pathol Oral Radiol 121: 496-509. 